\title{
Volcanic environments: "biomonitoring" their links to thyroid cancer
}

\author{
Leonidas H. Duntas ${ }^{1}$
}

Received: 13 April 2016/Accepted: 27 April 2016/Published online: 9 May 2016

(C) Springer Science+Business Media New York 2016

\begin{abstract}
May not subterraneous fire be considered as the great plough which Nature makes use of to turn up the bowels of the Earth?
\end{abstract}

Sir William Hamilton (English diplomat, archaeologist and geologist) ${ }^{1}$

Thyroid cancer is on the increase in many parts of the world, in particular the papillary histotype and its follicular variant. Meanwhile, microcarcinomas are multiplying at a faster rate than larger tumors, although it has recently been reported that more aggressive forms are also on the rise [1-3]. While this upsurge in thyroid cancer incidence has been attributed by a number of researchers to the increasing application of sophisticated image technology, an array of environmental factors may also be inculpated [4]. Thus, increased exposure to radiation, nutritional determinants as high intake of iodine and selenium deficiency, and certain industrialized carcinogens in our industrialized lifestyle are all likely to be involved [5].

In the past few decades, volcanic areas have also been associated with increased incidence of papillary thyroid cancer (PTC). This has put volcanology in the spotlight for the purpose of deciphering the putative mechanisms generating the disease, while also exploring the potential of this natural phenomenon to act as a disease promoter. For example, in a register-based epidemiologic study it was

Leonidas H. Duntas

ledunt@otenet.gr

1 Evgenideion Hospital, Unit of Endocrinology, Diabetes and Metabolism, Thyroid Section, University of Athens, 20 Papadiamantopoulou, 11528 Athens, Greece shown that residents of Catania province, Sicily, living in proximity to Italy's largest volcano, Mount Etna, had a higher incidence of PTC than the population of the rest of Sicily [6]. Although there are objective limitations to interpreting findings from population-based registries, the intensity of screening carried out in special centers in the vicinity of the volcano should be carefully considered while also bearing in mind the geophysical factors [7].

In this connection, of particular interest is the paper by Malandrino et al., recently published in Endocrine [8], which sheds considerable light on the present topic and offers a degree of insight into the various pathways linking volcanoes to development of thyroid cancer [8]. The authors conducted a cohort comparison study, evaluating a number of environmental pollutants in the water and atmosphere, in residents of the volcanic area surrounding Mount Etna in the province of Catania and in a control area.

In the volcanic region, they laid emphasis on assessment of the level of biocontamination by the "trace element pollution" produced by eruptions, which, inevitably, modifies the surroundings. This ultimately impacts human health, since retention of these elements in the soils results in their being readily transferred into water and plants, and so on up the food chain. Based on data obtained from the Sicilian Regional Registry for Thyroid Cancer, thyroid cancer incidence doubled in the volcanic area as compared to the control area (from 18.5 to 9.6/105 inhabitants in the volcanic and the control areas, respectively), the increase concerning mainly the papillary histotype. In the volcanic area, several trace elements were increased in both drinking water, in particular, and in lichens as compared to the control area, hence demonstrating water as well as atmospheric pollution [8].

$\overline{1}$ Observations on Mt Vesuvius, Mt Etna and other volcanoes (1774). 
The number of trace elements was also elevated in urine, revealing a complex non-anthropogenic biocontamination involving a number of trace elements and, once again, signifying both water and atmospheric pollution. These findings considerably add to the epidemiological evidence of higher than average thyroid carcinogenesis in the volcanic regions that compose the "rings of fire" around the world [9]. Importantly, however, they indicate that "trace element pollution" could be causally involved in the development of papillary thyroid carcinomas in volcanic and in non-volcanic areas alike.

In this line of evidence, a recent study evaluated the regional atmospheric deposition before and after the eruption of the Puyehue-Cordón Caulle volcano in Northern Patagonia and tested patterns of bioaccumulation using Usnea barbata lichen transplants as a biomonitor of comparison between two sampling campaigns [10]. Following the eruption, lichens accumulated significantly higher median levels of various elements, including boron, chromium, iron, and selenium (Se), thus reflecting the levels of elements in the environment on a large scale: this fact illustrates the potential for the natural transfer of volcanic ash and emissions to distant places. An eruption produces high amounts of such gases as radon-222, a radioactive gas generated from the decay of uranium-238. Nevertheless, while radon-222 was found to be produced during intensive eruptive episodes of Mount Etna and other volcanoes, no evidence as yet exists that radon exposure is associated with thyroid cancer [11].

\section{Basaltic and dormant volcanoes}

An issue of considerable relevance to this review is the estimated activity of the volcano in question, apart from human proximity to it. A study based on a hospital-registry in the Campania region of Italy where Vesuvius is located showed increased incidence and earlier development of TC in the population residing around the volcano as compared to other areas of the region [12]. By contrast, a population study in the same region using a different registry did not find any significant difference in the incidence of TC between the area around Vesuvius and the rest of the region [7]. Nevertheless, in neither case was the incidence as high as in Sicily, while, additionally, nor were certain elements such as vanadium observed to be increased, indicating that the activity of the volcano (Etna is classified as a basalticvolcano) is determinant. Etna is, in fact, the most active volcano in Europe, regularly erupting every few decades, in contrast to Vesuvius, the most active volcano on the European mainland, which, however, is dormant in its present phase.

\section{The role of sulfur and other volcanic trace elements in thyroid dysfunction}

Thus, the generally found increased incidence of TC in volcanic areas points to a multifactorial generation of disease. However, even more important is the evidence that sulfur-containing ash (among several other trace elements) spewed by volcanic eruptions leaves a prolonged imprint of sulfur in soil-to such a degree that frequently in many areas there is no further need to add sulfur to fertilizer applications. The presence of sulfur in biocontaminated environments has a particularly strong impact on selenium deficiency in soils, and as a result in humans, with possibly serious consequences for thyroid health. More specifically, ash-borne sulfur concentrations ejected by volcanoes may, by competition, cause mineral deficiency and trace element interferences and, specific to the present study, it is known that sulfur competes with Se for uptake by plants, resulting in decreased availability of Se compounds. In the human body, Se is incorporated in the form of selenocysteine in various selenoproteins. The fact that a crucial role is played by selenoproteins in thyroid gland function (deiodinases) and in redox status (glutathione peroxidases, GPXs and thioredoxin, TRX) [13] means that the above-described decrease in Se can lead to selenoprotein dysfunction, protein misfolding, and inflammation. Depending on the degree and duration of Se deficiency, the depletion of the Se storage protein selenoprotein P (SEPP), combined with GPX and TRX dysfunction, can result in oxidative stress and a high generation of radical oxygen species (ROS), which consequently triggers the intrathyroid production of TRX. TRX is a multifunctional redox protein which is likely to enhance the growth of cancer cells [13]. In the cytoplasm and nuclei of thyroid cancer cells, expression of TRX and TRX-receptor (TRX-R) was correlated and was observed to be increased as compared to normal thyroid parenchyma. This indicates that TRX and TRX-R might be associated with tumorigenesis and act as autocrine growth factors [14]. The occurrence of oxidative stress within thyroid cells stimulates TRX-R release, which, possessing strong anti-apoptotic activity inhibits apoptosis and induces abnormal cell proliferation, which may thus contribute to carcinogenesis (Fig. 1). It has been proposed that one extracellular function of TRX released by cancer cells is to promote the invasive phenotype [14]. It is noteworthy that thioredoxin interacting protein (TXNIP), a novel tumor suppressor, was found to be upregulated in aggressive thyroid tumors when peroxisome proliferator-activated receptor gamma (PPAR $\gamma)$, which confers an aggressive phenotype in thyroid cancer cells when it is overexpressed, is downregulated [15]. This has focused attention on 


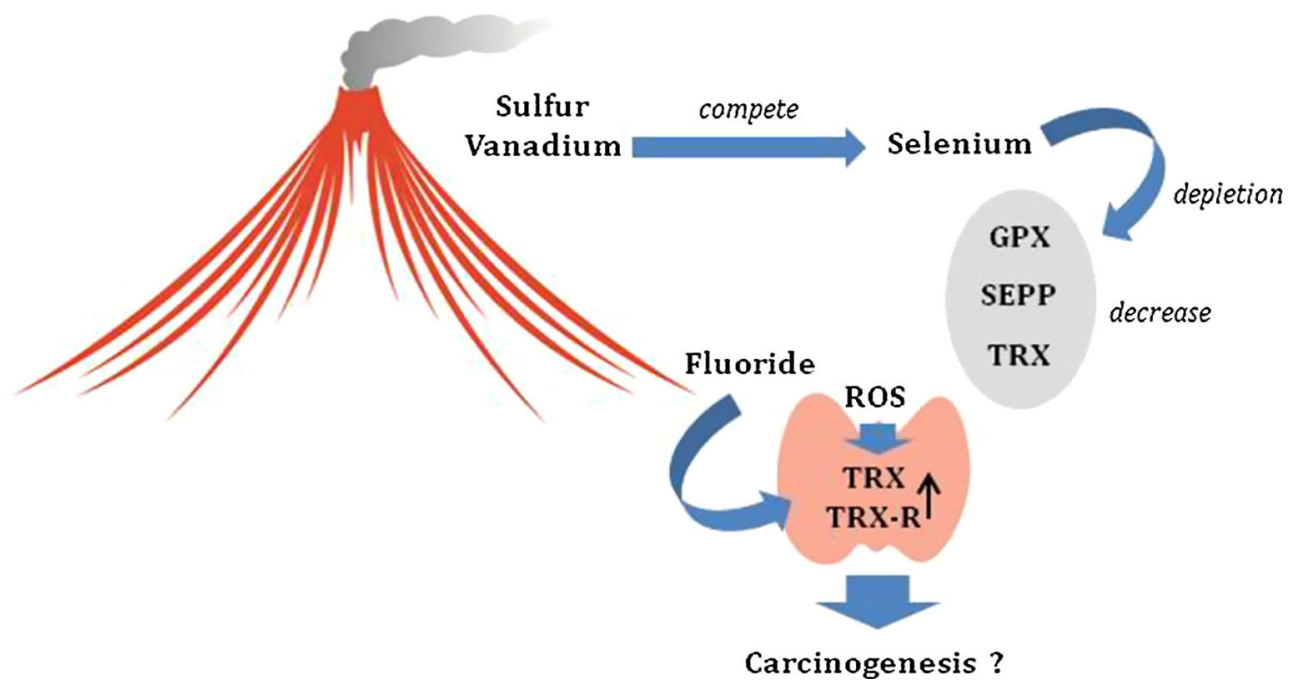

Fig. 1 Following a volcanic eruption, sulfur, vanadium, and many other elements accumulate in the soil and groundwater supply. Sulfur and to a lesser extent vanadium compete with selenium uptake by plants, resulting in selenium deficiency in soils and eventual progressive selenium deficiency in humans. In addition, fluoride, which is abundantly emitted by volcanic eruptions, has an inhibitory action on iodine symporter and thyroid hormone synthesis and is thus liable to disrupt thyroid function. Depending on the severity of

TXNIP as an indicator of advanced disease and identified its potential as a therapeutic target. However, the relationship of TXNIP to TRX and TRX-R in thyroid cells has yet to be thoroughly elucidated.

In parallel, other elements produced by volcanic eruptions, such as vanadium, manganese, iron, may interfere with thyroid hormone synthesis or fluoride, which effect causes thyroid dysfunction. It is thought that fluoride inhibits the activity of certain metabolic enzymes like $\mathrm{Na}(+)-\mathrm{K}(+)$-ATPase and thyroid peroxidase, thereby disrupting thyroid hormone production (Fig. 1).

There is thus accumulating evidence that volcanic areas are variably involved in the pathogenesis of thyroid cancer. The findings reported in the paper by Malandrino et al. [8] have underscored the importance of the content of gas emissions and the need for precise information on chemical and physical exposures of the contaminated soil in volcanic areas. Biomonitoring of the bioaccumulation caused by eruptions in active volcanic areas will result in a better understanding of the elements involved so that preventive measures, possibly nutritional, can be implemented. To this end there is a need to define the exact mechanisms of the abovementioned biocontamination especially of water supplies and of soils/plants leading to thyroid dysfunction and inflammation, as well as the likely epigenetic impact. Finally, investigation into the ambiguous role of TRX and TRX-R in disease development will shed more light on the issue. deficiency, this may lead to dysfunction of selenoproteins, which are important for antioxidant (glutathione peroxidases, GPX) and redox (thioredoxin TRX) functions as well as for selenium storage and transport (selenoprotein P, SEPP). The latter can facilitate the generation of radical oxygen species (ROS), triggering the TRX response and TRX-receptor (TRX-R) overexpression. Intrathyroid overactivity of TRX correlates with TRX-R and may contribute to carcinogenesis

\section{Compliance with ethical standards}

Conflict of interest The author declares that he has no conflict of interest.

\section{References}

1. B. Aschebrook-Kilfoy, R.H. Grogan, M.H. Ward, E. Kaplan, S.S. Devesa, Follicular thyroid cancer incidence patterns in the United States, 1980-2009. Thyroid 23, 1015-1021 (2013). doi:10.1089/thy. 2012.0356

2. L. Davies, H.G. Welch, Increasing incidence of thyroid cancer in the United States, 1973-2002. JAMA 295, 2164-2167 (2006)

3. A.Y. Chen, A. Jemal, E.M. Ward, Increasing incidence of differentiated thyroid cancer in the United States, 1988-2005. Cancer 115, 3801-3807 (2009). doi:10.1002/cncr.24416

4. E. Cardis, A. Kesminiene, V. Ivanov, I. Malakhova, Y. Shibata, V. Khrouch, V. Drozdovitch, E. Maceika, I. Zvonova, O. Vlassov et al., Risk of thyroid cancer after exposure to ${ }^{131} \mathrm{I}$ in childhood. JNCI 97, 724-732 (2005). doi:10.1093/jnci/dji129

5. M.A. Marcello, P. Malandrino, J.F.M. Almeida, M.B. Martins, L.L. Cunha, N.E. Bufalo, G. Pellegriti, L.S. Ward, The influence of the environment on the development of thyroid tumors: a new appraisal. Endocr. Relat. Cancer 21, 235-254 (2014)

6. G. Pellegriti, F. De Vathaire, C. Scollo, M. Attard, C. Giordano, S. Arena, G. Dardanoni, F. Frasca, P. Malandrino, F. Vermiglio, D.M. Previtera, G. D’Azzò, F. Trimarchi, R. Vigneri, Papillary thyroid cancer incidence in the volcanic area of Sicily. J. Natl. Cancer Inst. 101, 1575-1583 (2009). doi:10.1093/jnci/djp354

7. L. Dal Maso, S. Franceschi, M. Lise, M. Fusco, R. Tumino, D. Serraino, Re: Papillary thyroid cancer incidence in the volcanic area of Sicily. J. Natl. Cancer Inst. 102, 914-915 (2010). doi:10.1093/ jnci/djq157 
8. P. Malandrino, M. Russo, A. Ronchi, C. Minoia, D. Cataldo, C. Regalbuto, C. Giordano, M. Attard, S. Squatrito, F. Trimarchi, R. Vigneri, Increased thyroid cancer incidence in a basaltic volcanic area is associated with non-anthropogenic pollution and biocontamination. Endocrine (2015). doi:10.1007/s12020-015-0761-0. [Epub ahead of print]

9. L.H. Duntas, C. Doumas, The 'rings of fire' and thyroid cancer. Hormones (Athens) 8, 249-253 (2009)

10. M.E. Conti, R. Jasan, M.G. Finoia, I. Iavicoli, R. Plá, Trace elements deposition in the Tierra del Fuego region (south Patagonia) by using lichen transplants after the Puyehue-Cordón Caulle (north Patagonia) volcanic eruption in 2011. Environ. Sci. Pollut. Res. Int. 23, 6574-6583 (2016). doi:10.1007/s11356-0155858-8

11. N. Goyal, F. Camacho, J. Mangano, D. Goldenberg, Evaluating for a geospatial relationship between radon levels and thyroid cancer in Pennsylvania. Laryngoscope 125, E45-E49 (2015). doi:10.1002/lary.24815
12. B. Biondi, D. Arpaia, P. Montuori, G. Ciancia, S. Ippolito, G. Pettinato, M. Triassi, Under the shadow of vesuvius: a risk for thyroid cancer? Thyroid 22, 1296-1297 (2012). doi:10.1089/thy. 2012.0002

13. J. Köhrle, Selenium and the thyroid. Curr. Opin. Endocrinol. Diabetes Obes. 20, 441-448 (2013). doi:10.1097/01.med. 0000433066.24541 .88

14. D.T. Lincoln, F. Al-Yatama, F.M. Mohammed, A.G. Al-Banaw, M. Al-Bader, M. Burge, F. Sinowatz, P.K. Singal, Thioredoxin and thioredoxin reductase expression in thyroid cancer depends on tumour aggressiveness. Anticancer Res. 30, 767-775 (2010)

15. J.A. Morrison, L.A. Pike, S.B. Sams, V. Sharma, Q. Zhou, J.J. Severson, A.C. Tan, W.M. Wood, B.R. Haugen, Thioredoxin interacting protein (TXNIP) is a novel tumor suppressor in thyroid cancer. Mol. Cancer 13, 62 (2014). doi:10.1186/1476-4598-13-62 